\title{
Comparison of Kinematic Characteristics of Upper Body according to the Shooting of Elite Disabled Archery Athletes
}

Taewhan Kim¹, JaeWon Lee², SeoungKi Kang ${ }^{3}$, KyuYeon Chae ${ }^{4}$, Sang-hyup Choi ${ }^{5}$, Yong-Gwan Song ${ }^{6}$

${ }^{1}$ Korea Institute of Sport Science, Seoul, Republic of Korea

2 Department of Special Physical Education, Yongln University, Gyeonggi-do, Republic of Korea

${ }^{3}$ Graduate School of Education, Yongln University, Gyeonggi-do, Republic of Korea

${ }^{4}$ Shanghai University of Sports, Shanghai, China

${ }^{5}$ Center for Sport Science in Jeju, Jeju, Shanghai, Republic of Korea

${ }^{6}$ Department of Marine Sports, Pukyong National University, Busan, Republic of Korea

Address Correspondence to: Yong-Gwan, Song, Ph.D.

Department of Marine Sports

Pukyong National University

45, Yongso-ro, Nam-gu, Busan, 48513, Republic of Korea

E-mail: ygsong@pknu.ac.kr

Sang-hyup, Choi, Ph.D. 
30 Abstract: The purpose of this study is to compare and analyze the kinematic characteristics of the upper limb segments during the archery shooting of Paralympic Wheelchair Class archers (ARW2 - second wheelchair class - paraplegia or comparable disability) and Paralympic Standing Class archers (ARST - standing archery class loss of 25 points in the upper limbs or lower limbs), where archers are classified according to their disability grade among elite disabled archers. The participants of this study were selected as seven elite athletes with disabilities, 4 ARW2, and 3 ARST. The analysis variables were 1) the time required for each phase, 2) the angle of inclination of the body center, 3) the change of trajectory of body center, and 4) the change of movement locus of bow center by phase when performing six shots in total. The ARW2 group showed a longer time than the ARST group, and the angle of the body did not show a significant difference between the two groups. Although there was no significant difference in the mean score between the two groups, it was judged that kinematic performance according to each group was, in that there was a measurable variation in kinematic variables. 


\section{Introduction}

Archery is a recorded event that determines the victory or defeat by scoring points by accurately using a bow and arrow to hit a target at a certain distance (Ha, Shin, \& Kim, 2006). The Paralympic started in 1960, the first Rome Paralympic Games, and the Republic of Korea participated in the 1968 Tel Aviv Paralympic Games in 1968. Among the participating events, the archery for handicapped is one of the representative sportsmen who have achieved excellent results since winning the gold medal in the Heidelberg Paralympics in 1972 (Korean Paralympic Committee, 2015).

World Archery defines functional classification of athletes based on limb impairment. Among them are two wheelchair classes: ARW1 (wheelchair first class - functional impairments in at least three limbs and trunk), ARW2 (second wheelchair class - paraplegia or comparable disability), and a standing class: ARST (standing archery class - loss of 25 points in the upper limbs OR lower limbs) according to the characteristics of the disability class (Kim, Song, \& Kim, 2008; World Archery, 2020). The game is played in the same way as the non-disabled archery, with the records and tournaments. The record matches are played in the men's 90M,70M, 50M and 30M (men's ARW1 are played in the same distance as the women) and $70 \mathrm{M}, 60 \mathrm{M}, 50 \mathrm{M}$, and $30 \mathrm{M}$ long distance $(90 \mathrm{M}, 70 \mathrm{M}, 50 \mathrm{M})$ is 6 points for 6 rounds, and the short distance $(50 \mathrm{M}, 30 \mathrm{M})$ is 36 rounds (total 144 rounds).

Since the archery should be operated repeatedly in the same posture by repeatedly aiming at the target like a shot, the consistency of the action is an essential factor in the performance (Kim, Lee, \& Kim, 2014). The archery also depends on how accurately the drawing and release are carried out, and for the expert, there is a little variation in the drawing phase. However, the most crucial technique for archery players was the technology of the release phase (Hah \& Yi, 2008). In a previous study on the importance of release in archery, the reaction time could be shortened without unnecessary power release and, shorter the reaction time, the better the performance (Kim \& Kim, 2005; Kim, 1996). Also attempted to analyze the consistency of postures for the first time in the field of archery, and as a result, it was reported that it is an essential factor to determine the performance when releasing the demonstration from the finger (Stuart \& Atha, 1990).

In the archery, motion capture using a high-speed camera is necessary to observe the subtle movement and the change of the shooting motion. Unfortunately, there are some studies on general archery players, but there are no studies that analyzed three - dimensional motion of elite disability archery athletes. Therefore, the present study aimed to 1) analyze the kinematic mechanism according to the shooting attitude of the elite wheelchair archery athletes and to provide a reference point for the archery athlete with disabilities. 2) in order to perform the sophisticated manipulation of archery skill, we tried to find out the movement time, movement of the body, the change of the center of the body, and the bow.

We hypothesized that 1) the time taken to prepare to shoot an arrow would differ between groups, 2) the angle of body tilt would not show any significant variation between groups, and 3) the movement trajectories of the body's center and bow center would vary from phase to phase. 


\section{Methods}

Participants in this study were four ARW2 class sitting in a wheelchair and shooting a bow and three ARST class standing and shooting a bow. The research was conducted with the consent of the Korea Archery Association for the Disabled and athletes.

In this study, all the national athletes were selected at the time of the experiment, except ARW1, which has a very high level of disability, and compound items with different bow types. The characteristics of the study participants are shown in Table 1.

Table 1. Characteristic of Participants.

\begin{tabular}{ccccc}
\hline Group & Years & Carrier(year) & Classification & $\begin{array}{c}\text { Length of } \\
\text { Arm(cm) }\end{array}$ \\
\hline Male & 45 & 7 & ARW2 & 69.85 \\
Male & 43 & 20 & ARW2 & 71.12 \\
Male & 52 & 17 & ARW2 & 74.93 \\
Female & 46 & 17 & ARW2 & 72.39 \\
Male & 51 & 5 & ARST & 69.21 \\
Female & 47 & 13 & ARST & 66.04 \\
Female & 46 & 8 & ARST & 69.85 \\
\hline
\end{tabular}

ARW2: paraplegia or comparable disability, ARST: loss of 25 points in the upper limbs OR lower limbs

The experimental equipment used in this study consisted of equipment for space coordinate calculation, imaging equipment, and analysis equipment (Table 2).

Table 2. Experimental Equipment.

\begin{tabular}{ccc}
\hline Division & Experiment Equipment & Manufacture Company \\
\cline { 2 - 2 } $\begin{array}{c}\text { Calculation and } \\
\text { Acquisition of Spatial } \\
\text { Coordinates }\end{array}$ & NLT & Motion Analysis \\
Motion Shooting & $\begin{array}{c}\text { Reflection Marker(12.7mm) } \\
\text { Motion Capture System }\end{array}$ & Motion Analysis \\
Motion Analysis & $\begin{array}{c}\text { Motion Analysis software } \\
\text { (cortex 1.3) }\end{array}$ & Motion Analysis \\
\hline
\end{tabular}

The experimental task of this study was to shoot a total of 6 shots at a total distance of $20 \mathrm{~m}$ (creating an environment for 3D motion analysis experiment). The total score of 6 rounds was 57 points for ARW2 group and 56 points for ARST group. The purpose of this study was to calibrate the spatial coordinates necessary for motion analysis in the experimental space until the inclusion of the experimental operation of the subject using the None Linear Transformation (NLT) technique. In this study, 12 dynamic real-time infrared cameras (Motion I.R., Eagle 4) were used in the front, rear, left, right, and diagonal directions to analyze the kinematic variables in archery shooting. The 
center of the body was based on the center of mass of the upper body, excluding the lower body, and the center of the bow was designated as the whole segment to be the center of mass. The sampling rate was $120 \mathrm{~Hz} / \mathrm{s}$, and the resolution of the sensor was set to $1280 \times 1024$ pixels. Also, the PD-170 for the 3-CCD method was used to record images using an IEEE1394 cable, and the shooting speed was set to 30 frames/sec (Fig. 1).

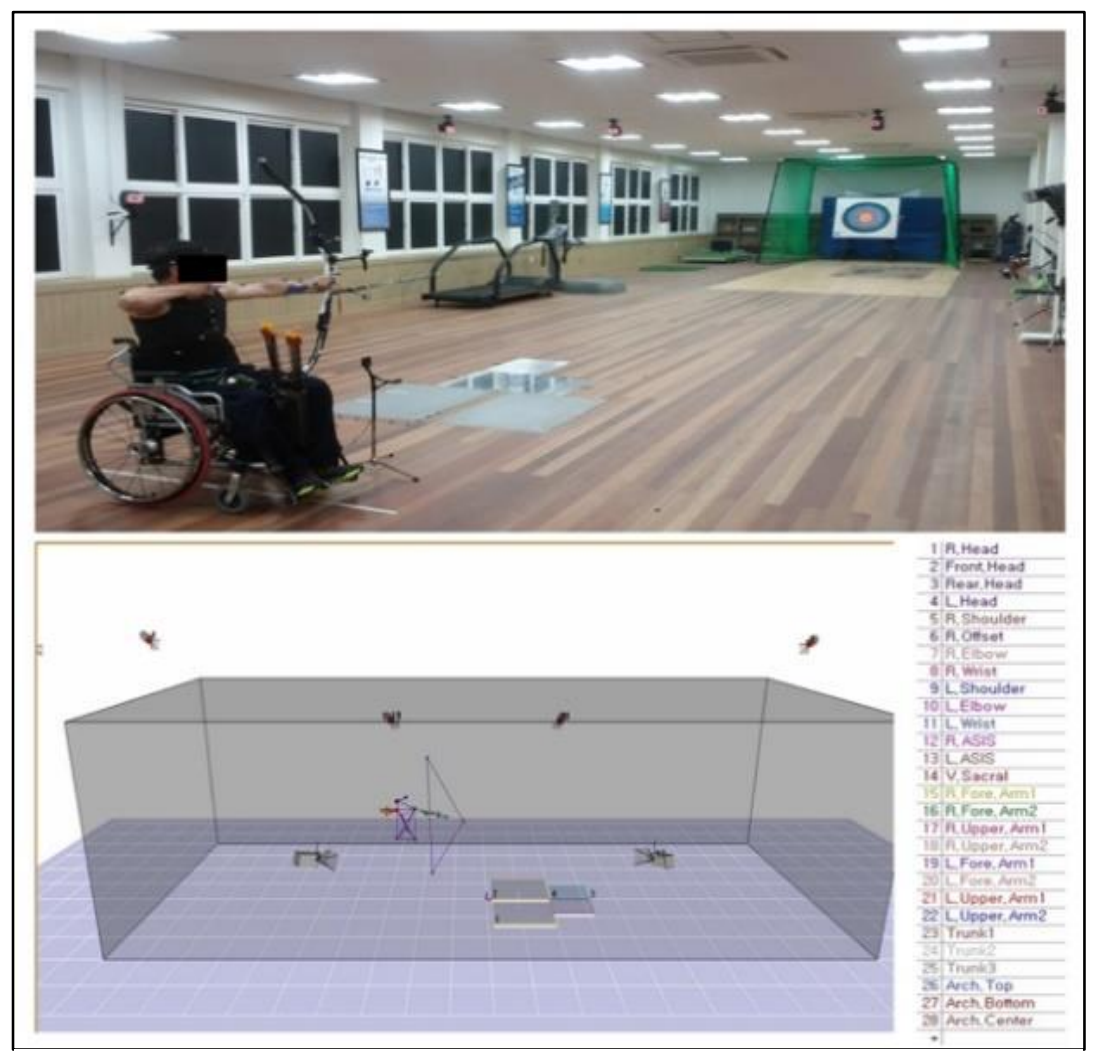

Figure 1. Experimental Layout.

Besides, the image data were analyzed using the Cortex 1.3 program (Motion Analysis, USA). The event of this study is composed of the events classified by each event in the study of Kim (2014) (Fig. 2).

a Drawing phase: From the starting point of drawing to the starting point of anchoring, which is the moment when the pulling arm is pulled and stopped completely.

b Holding phase: From the beginning of holding to the moment when the finger holding the protest starts releasing.

c Release phase: From the start of the release to the beginning of the follow-through, which is the moment when the arrow has completely deviated from the bow.

d Follow through a phase: From the start of the follow-up to the end of the follow-up after the 
end of the rotating bow passes through the waist.

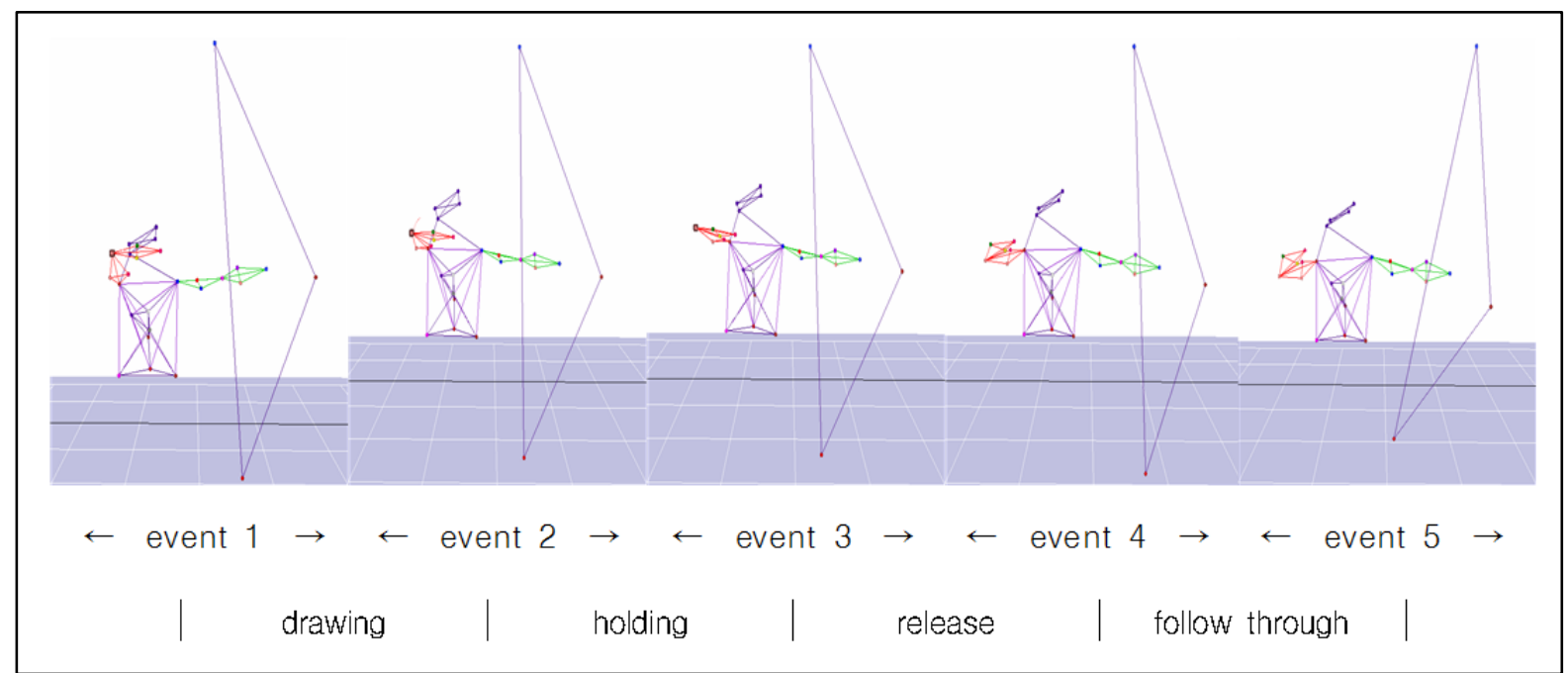

Figure 2. Analytics Events and Phases. The experimental movement of the study is divided into five events and four phases.

To the purpose of this study, a total of twenty-eight reflective markers were attached to the upper segment, and bow using reflection marker, and the standing calibration was performed to calculate the joint center. After a total of 6 shots were shot, the average score was analyzed. The kinematic variables in the experiment were the time required for each phase, the front and back of the body, the inclination angles of the left and right, the movement locus of the upper body, and the movement locus of the center of the bow. In order to analyze the change in characteristics of archery shooting behavior of the disabled (ARW2, ARST), an independent sample t-test was conducted using IBM SPSS 25.0 Ver. (SPSS Inc., USA). The significance level was set at $p<.05$. To analyze the group's reliability in six shots, calculating the coefficient of intraclass correlation is determined to be reliable, with an average measure of .852. Approval was obtained from the study center's ethics committee (Local Ethics Committee of Institute of Sport Sciences, ref. 8-B-3727) and the ethics committees of the other collaborating partners. All participants provided informed consent. 
172

173

174

175

176

177

178

179

180

181

182

183

184

\section{Results}

Time required by each phase

First, the analysis of the time required for each phase (from drawing to follow-through) was performed. The independent sample t-test was conducted to examine whether there are significant differences in the main variables according to the stocks (groups). As a result, there was a significant difference in the drawing and holding phase between the time of drawing and $t=4.048, p<.05$ and $t=2.971, p<.05$ according to the items. ARW2 group $(M=2.3)(M=0.98)$. Also, in the holding phase, the ARW2 group ( $M=4.41$ ) was longer than the ARST group ( $M=3.04$ ). On the other hand, there were no significant differences in the release and follow-through phases according to the items (Table 3, Fig. 3).

Table 3. Time required by each phase

\begin{tabular}{|c|c|c|c|c|c|c|c|}
\hline \multicolumn{2}{|c|}{ Dependent Variable } & Group & $\begin{array}{c}\text { Number of } \\
\text { Samples }\end{array}$ & mean & $\begin{array}{l}\text { Standard } \\
\text { deviation }\end{array}$ & $\mathrm{t}$ & $\mathrm{p}$ \\
\hline \multirow{8}{*}{$\begin{array}{l}\text { Time } \\
\text { required } \\
\text { by } \\
\text { each } \\
\text { phase }\end{array}$} & \multirow{2}{*}{ drawing } & ARW2 & 4 & 2.228 & 0.517 & \multirow{2}{*}{$3.703^{*}$} & \multirow{2}{*}{0.014} \\
\hline & & ARST & 3 & 0.985 & 0.288 & & \\
\hline & \multirow{2}{*}{ holding } & ARW2 & 4 & 4.414 & 0.845 & \multirow{2}{*}{$2.619^{*}$} & \multirow{2}{*}{0.047} \\
\hline & & ARST & 3 & 3.042 & 0.322 & & \\
\hline & \multirow{2}{*}{ release } & ARW2 & 4 & 0.297 & 0.041 & \multirow{2}{*}{-0.452} & \multirow{2}{*}{0.670} \\
\hline & & ARST & 3 & 0.324 & 0.111 & & \\
\hline & follow & ARW2 & 4 & 0.343 & 0.060 & \multirow{2}{*}{-1.546} & \multirow{2}{*}{0.183} \\
\hline & through & ARST & 3 & 0.513 & 0.215 & & \\
\hline
\end{tabular}

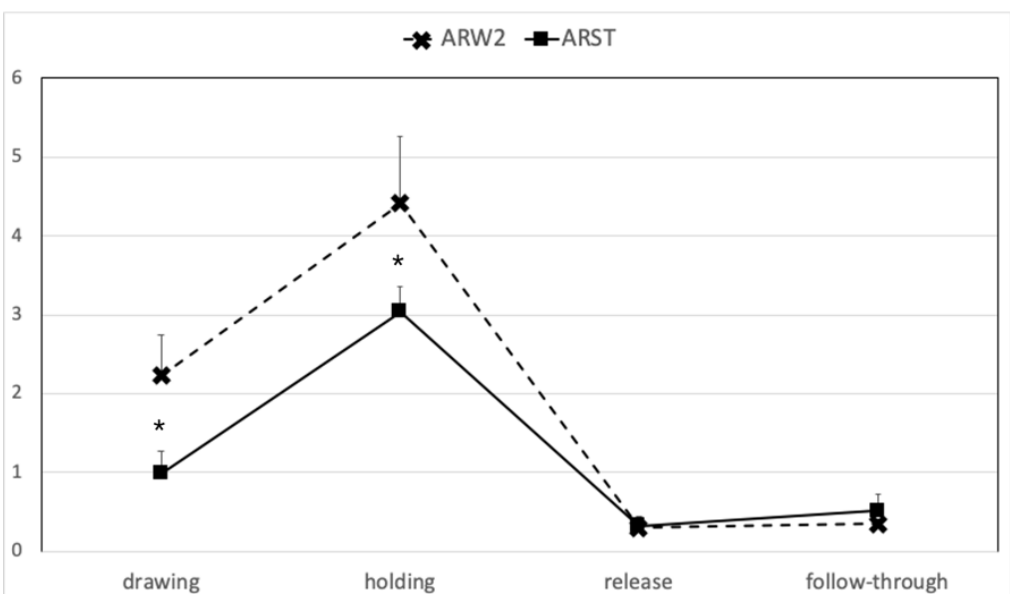

Figure 3. Time required by each phase deviation line graph. 
191 The angle of inclination of the body by event.

192 As a result of the t-test of the tilt angle (left and right, anterior and posterior) of the body, there

193 was no significant difference between the two groups (E1 to E5) (Table. 4, Fig. 4, 5).

194

195

Table 4. The angle of inclination of the body by event.

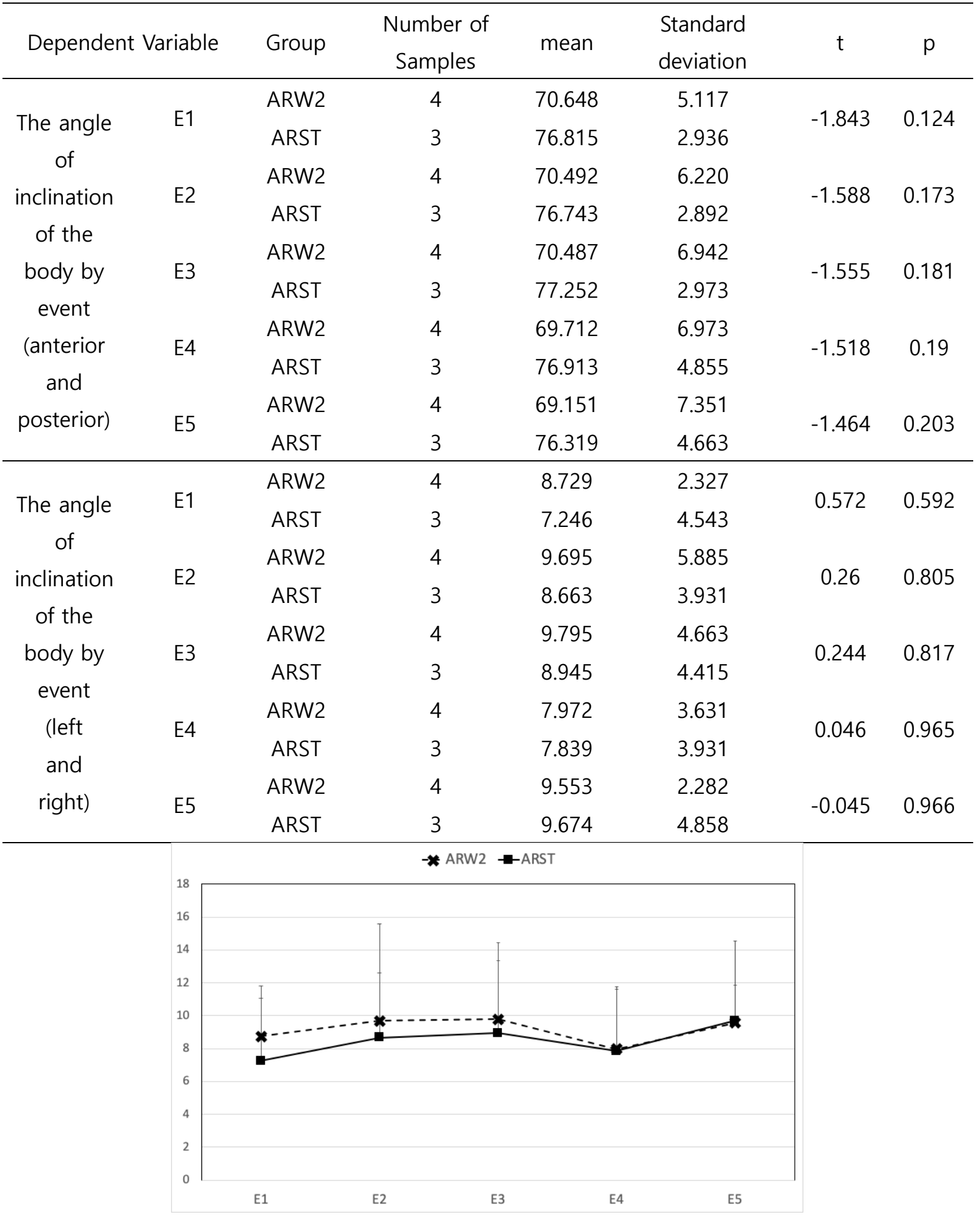

Figure 4. The angle of inclination of the body by event deviation line graph (Left and Right). 


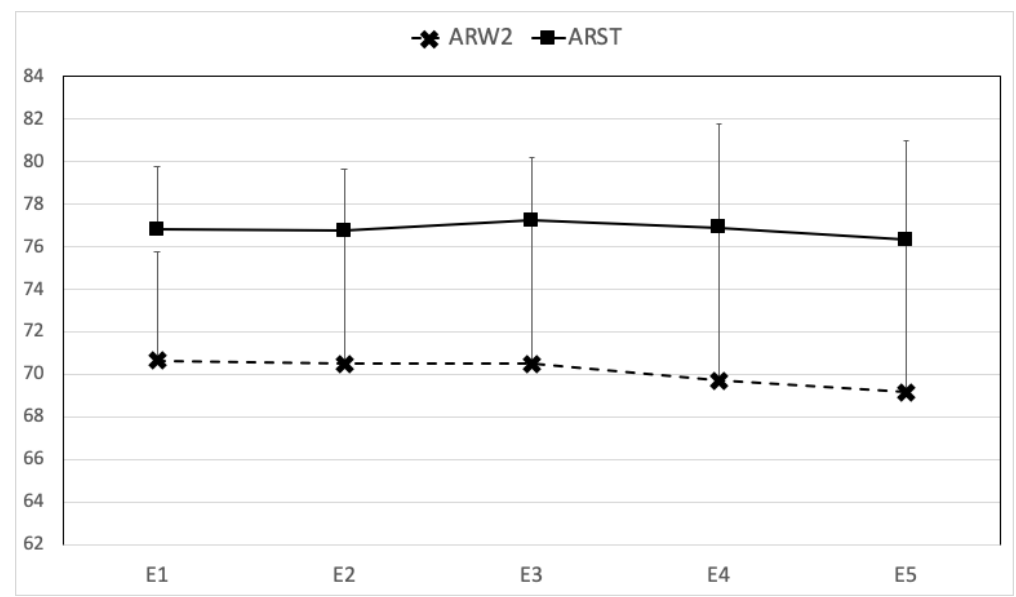

Figure 5 . The angle of inclination of the body by event deviation line graph (Anterior and Posterior).

198

199

200

201

202

203

204

205

206

207

Table 5. Change of trajectory of body center.

\begin{tabular}{|c|c|c|c|c|c|c|c|}
\hline Dependen & t Variable & Group & $\begin{array}{c}\text { Number of } \\
\text { Samples }\end{array}$ & mean & $\begin{array}{l}\text { Standard } \\
\text { deviation }\end{array}$ & $\mathrm{t}$ & $p$ \\
\hline \multirow{15}{*}{$\begin{array}{l}\text { Change } \\
\text { of } \\
\text { trajectory } \\
\text { of body } \\
\text { center }\end{array}$} & \multirow{2}{*}{ drawing_X } & ARW2 & 4 & 1.875 & 0.365 & \multirow{2}{*}{2.297} & \multirow{2}{*}{0.07} \\
\hline & & ARST & 3 & 1.098 & 0.539 & & \\
\hline & \multirow{2}{*}{ drawing_Y } & ARW2 & 4 & 1.013 & 0.288 & \multirow{2}{*}{$3.523^{*}$} & \multirow{2}{*}{0.017} \\
\hline & & ARST & 3 & 0.292 & 0.235 & & \\
\hline & \multirow{2}{*}{ drawing_Z } & ARW2 & 4 & 5.522 & 1.783 & \multirow{2}{*}{0.972} & \multirow{2}{*}{0.376} \\
\hline & & ARST & 3 & 4.209 & 1.745 & & \\
\hline & \multirow{2}{*}{ holding_X } & ARW2 & 4 & 0.739 & 0.102 & \multirow{2}{*}{0.38} & \multirow{2}{*}{0.72} \\
\hline & & ARST & 3 & 0.711 & 0.086 & & \\
\hline & \multirow{2}{*}{ holding_Y } & ARW2 & 4 & 0.375 & 0.312 & \multirow{2}{*}{0.784} & \multirow{2}{*}{0.469} \\
\hline & & ARST & 3 & 0.211 & 0.206 & & \\
\hline & \multirow{2}{*}{ holding_Z } & ARW2 & 4 & 1.316 & 1.617 & \multirow{2}{*}{0.221} & \multirow{2}{*}{0.834} \\
\hline & & ARST & 3 & 1.094 & 0.667 & & \\
\hline & \multirow{2}{*}{ release_X } & ARW2 & 4 & 1.455 & 0.354 & \multirow{2}{*}{0.098} & \multirow{2}{*}{0.926} \\
\hline & & ARST & 3 & 1.432 & 0.211 & & \\
\hline & release_Y & ARW2 & 4 & 0.301 & 0.190 & 0.5 & 0.638 \\
\hline
\end{tabular}

Change of trajectory of body center by phase.

As a result of the t-test on the $X$-direction (left and right), $Y$ (forward and backward) and $Z$ (up and down) directions of the upper body in each phase among the kinematic variables of the posture during the archery shooting, $(T=3.644, p<.05)$ and the ARW2 group $(M=1.01)$ showed a more significant $Y$-axis change rate than the ARST group $(M=0.29)$. On the other hand, the change of the center-of-gravity movement trajectory in the remainder of the drawing phase except the $Y$ axis was not significantly different between the two groups (Table 5, Fig. 6). 


$\begin{array}{ccccccc} & \text { ARST } & 3 & 0.236 & 0.138 & & \\ \text { release_Z } & \text { ARW2 } & 4 & 0.990 & 0.152 & -0.884 & 0.417 \\ \text { Follow } & \text { ARST } & 3 & 1.349 & 0.819 & & \\ \text { through_X } & \text { ARW2 } & 4 & 1.727 & 0.115 & -1.282 & 0.328 \\ \text { Follow } & \text { ARST } & 3 & 3.335 & 2.171 & & \\ \text { through_Y } & \text { ARST } & 3 & 0.651 & 0.426 & -0.937 & 0.392 \\ \text { Follow } & \text { ARW2 } & 4 & 0.928 & 0.317 & & \\ \text { through_Z } & \text { ARST } & 3 & 3.171 & 1.114 & -1.368 & 0.23\end{array}$

208

209

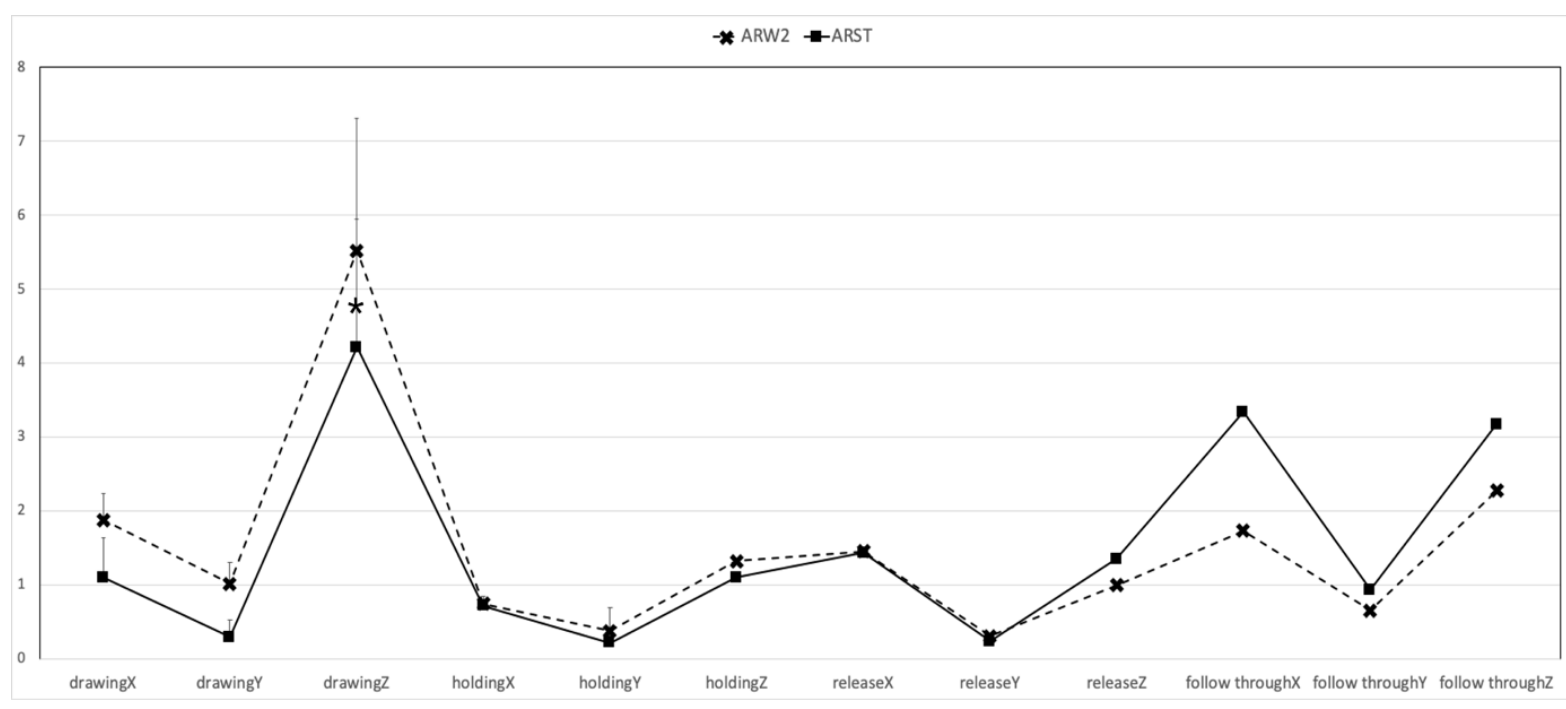

Figure 6. Change of trajectory of body center by phase.

210

Change of movement locus of bow center by phase.

212 There was no significant difference between the groups when the archery was shot, $t$-test results of $X$ (left and right axis), $Y$ (longitudinal axis), and $Z$ (vertical axis) (Table. 6, Fig. 7).

Table 6. Change of movement locus of bow center by phase.

\begin{tabular}{|c|c|c|c|c|c|c|c|}
\hline Dependen & Variable & Group & $\begin{array}{c}\text { Number of } \\
\text { Samples }\end{array}$ & mean & $\begin{array}{l}\text { Standard } \\
\text { deviation }\end{array}$ & $\mathrm{t}$ & $p$ \\
\hline \multirow{8}{*}{$\begin{array}{l}\text { Change } \\
\text { of } \\
\text { trajectory } \\
\text { of body } \\
\text { center }\end{array}$} & \multirow{2}{*}{ drawing_X } & ARW2 & 4 & 0.631 & 0.240 & \multirow{2}{*}{1.489} & \multirow{2}{*}{0.197} \\
\hline & & ARST & 3 & 0.387 & 0.170 & & \\
\hline & \multirow{2}{*}{ drawing_Y } & ARW2 & 4 & 0.252 & 0.154 & \multirow{2}{*}{0.312} & \multirow{2}{*}{0.768} \\
\hline & & ARST & 3 & 0.221 & 0.079 & & \\
\hline & \multirow{2}{*}{ drawing_Z } & ARW2 & 4 & 0.917 & 0.332 & \multirow{2}{*}{1.436} & \multirow{2}{*}{0.21} \\
\hline & & ARST & 3 & 0.583 & 0.260 & & \\
\hline & \multirow{2}{*}{ holding_X } & ARW2 & 4 & 0.208 & 0.078 & \multirow{2}{*}{-1.305} & \multirow{2}{*}{0.249} \\
\hline & & ARST & 3 & 0.274 & 0.041 & & \\
\hline
\end{tabular}




\begin{tabular}{|c|c|c|c|c|c|c|}
\hline \multirow{2}{*}{ holding_Y } & ARW2 & 4 & 0.113 & 0.102 & \multirow{2}{*}{0.151} & \multirow{2}{*}{0.886} \\
\hline & ARST & 3 & 0.103 & 0.047 & & \\
\hline \multirow{2}{*}{ holding_Z } & ARW2 & 4 & 0.169 & 0.139 & \multirow{2}{*}{0.019} & \multirow{2}{*}{0.985} \\
\hline & ARST & 3 & 0.167 & 0.092 & & \\
\hline \multirow{2}{*}{ release_X } & ARW2 & 4 & 0.307 & 0.303 & \multirow{2}{*}{0.706} & \multirow{2}{*}{0.511} \\
\hline & ARST & 3 & 0.179 & 0.053 & & \\
\hline \multirow{2}{*}{ release_Y } & ARW2 & 4 & 0.195 & 0.154 & \multirow{2}{*}{0.91} & \multirow{2}{*}{0.405} \\
\hline & ARST & 3 & 0.111 & 0.035 & & \\
\hline \multirow{2}{*}{ release_Z } & ARW2 & 4 & 0.238 & 0.097 & \multirow{2}{*}{0.081} & \multirow{2}{*}{0.939} \\
\hline & ARST & 3 & 0.230 & 0.174 & & \\
\hline Follow & ARW2 & 4 & 0.416 & 0.249 & \multirow{2}{*}{-0.813} & \multirow{2}{*}{0.453} \\
\hline through_X & ARST & 3 & 0.553 & 0.168 & & \\
\hline \multirow{2}{*}{$\begin{array}{c}\text { Follow } \\
\text { through_Y }\end{array}$} & ARW2 & 4 & 0.232 & 0.198 & \multirow{2}{*}{-0.292} & \multirow{2}{*}{0.782} \\
\hline & ARST & 3 & 0.283 & 0.271 & & \\
\hline \multirow{2}{*}{$\begin{array}{c}\text { Follow } \\
\text { through_Z }\end{array}$} & ARW2 & 4 & 0.092 & 0.052 & \multirow{2}{*}{-0.969} & \multirow{2}{*}{0.432} \\
\hline & ARST & 3 & 0.304 & 0.375 & & \\
\hline
\end{tabular}

216

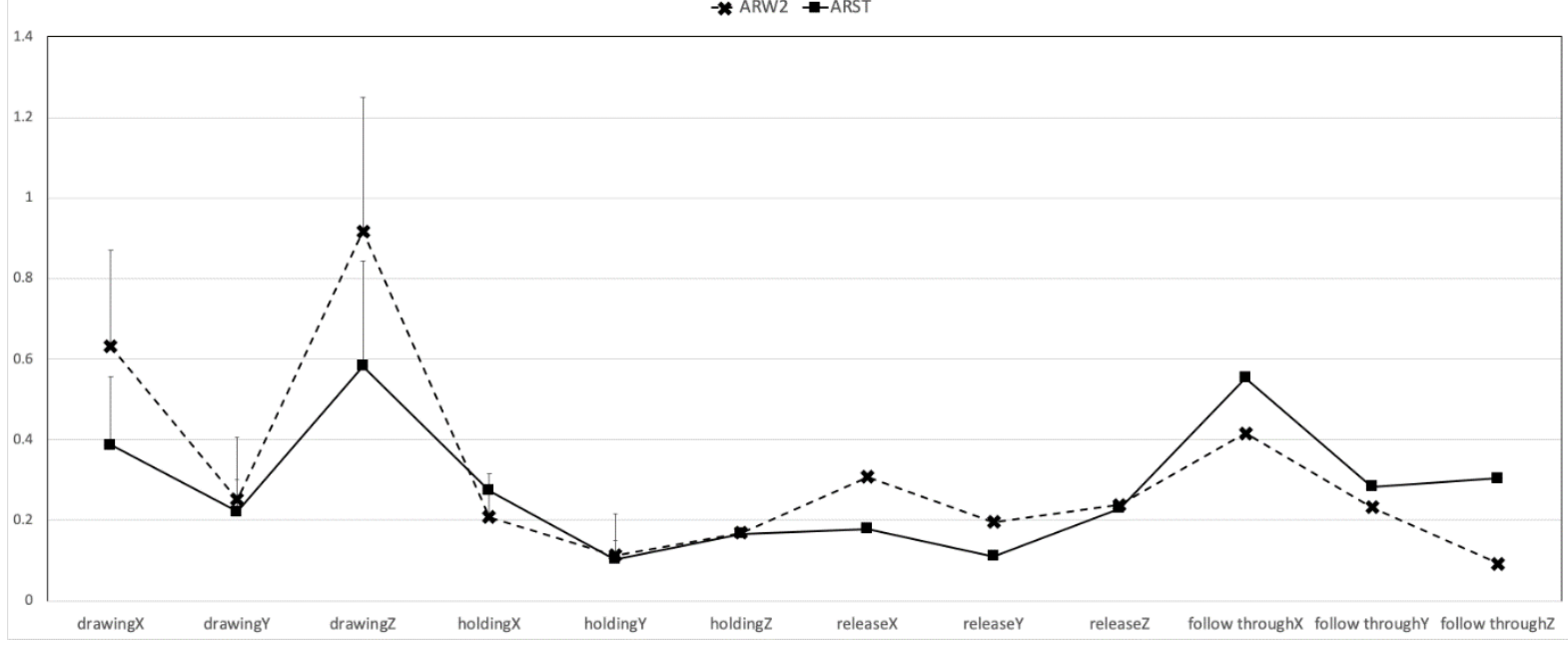

Figure 7. Change of movement locus of bow center by phase.

218

219

220

221

222 


\section{Discussion and implication}

The purpose of this study is to analyze the kinematic characteristics of elite disabled archers by classifying them as ARW2 and ARST of the archery class of handicapped. Then, the time required for each phase, the angle of tilt of the body by each event, the change of the trajectory of the center of the upper body and the change of the trajectory of the center of the bow were examined.

The ARW2 group had 1.243 seconds longer in the drawing phase and 1.372 seconds longer in the holding phase compared to the ARST group. On the other hand, although the difference was not significant, the ARST group showed a longer time than the ARW2 group in the release phase and the follow-through phase. In support of this, according to the study of the shooting behavior of elite archery athletes, the total duration of the athletes' performance was about 6 seconds in the study of shooting behavior of the elite archery athlete, Second, holding phase averaged $2.53 \mathrm{sec}$, release phase averaged $0.05 \mathrm{sec}$, and follow-through phase averaged $0.56 \mathrm{sec}(\mathrm{Kim} \& \mathrm{Kim}, 2006)$.

Based on these previous studies, the ARW2 group showed a relatively long time in the drawing phase and the holding phase. Because ARW2 group characteristics are significantly lower than the ARST group, it would be expected that more time would have been required to balance the pulling force. In the release phase and the follow-up phase, contrary to the previous phase, the ARST group showed a longer time than the ARW2 group because of the structural difference between ARW2, which is a way of sitting in a wheelchair, and ARST, amount of change in the displacement of the hand in the direction of the ground is considerable. The results of this study are as follows. First, the results of this study are as follows (Kim, Lee, \& Kim, 2014). Second, there was no significant difference between the two groups in all events. However, when the body angle was 90 degrees, it was found that the ARW2 group tilted backward more than the ARST group.

In archery, the closer the body is to $90^{\circ}$, the more stable the posture by aligning the arm and body skeleton pushing the bow to reduce the energy and reduce the shaking of the bow by the bow repulsion (Lee, Hah, Ryu, \& Kim, 2007). Therefore, it is considered that the body of the ARST group is closer to $90^{\circ}$ due to the low degree of disability (or due to the advantages of standing motion). Besides, there was no significant difference between the left and right tilt angles. However, the ARW2 group tended to climb higher on the left shoulder than the ARST group. ARW2 group tilted backward at the anterior and posterior tilts of the trunk, and this was connected to the upward movement of the left shoulder. The changes in the trajectory of the upper body center showed a significant difference between the two groups in the $Y$ direction (before and after the trailing axis) in the drawing phase. It means that the body center is more stable in the anterior and posterior direction than the ARW2 group. In a previous study supporting this, a comparison of COM scores between good and bad scores of 8 female archery athletes showed that the score of COM was smaller, indicating a smaller trajectory of COM movement (Kim, Lee, \& Kim, 2014). The inclination of the body and the inclination of both shoulders, as described above, are also closely related to the upper body center.

On the other hand, the ARST group showed a smaller COM movement trajectory than the ARW2 group in the remaining drawing, holding phase and direction, and $X$ (left and right) and $Y$-axis of 
267 the release phase. Also, Z (upper, lower axis) and the follow-up phase of the release phase, and the overall direction showed a more massive shift of the center locus of motion, which is due to the movement of the upper body. It is also thought that it was affected by the trajectory. As a precedent study to support this, when the athlete who won the gold medal at the Athens Olympic archery group in 2004, the body center of gravity change in each phase was decreased by $1.21 \mathrm{~cm}$ (Kim $\&$ Kim, 2006). Finally, there was no significant difference between the two groups in the shift of the locus of movement. It can be noted that the ARW2 group is significantly smaller than the ARST group in the follow-up phase, which is considered to be influenced by the fall of the bow as described above. 


\section{Conclusion}

307 The duration of archery shooting was longer in the drawing and holding phases of the ARW2

308 group than in the ARST group, and the overall shooting time was longer in the ARW2 group. Also, the body tilt angle was not different between the two groups, but the ARST group showed a smaller change in the body tilt angle. The change in body movement trajectory showed a more significant change in the ARW2 group than the ARST group in front and rear direction in the drawing phase. Lastly, there was no significant difference in the movement trajectory of the bow center between

313 the two groups.

314

315

316

317

318

319

320

321

322

323

324

325

326

327

328

329

330

331

332

333

334

335

336

337

338

339

340

341

342

343 
345

346

347

348

349

350

351

352

353

354

355

356

357

358

359

360

361

362

363

364

365

366

367

\section{References}

Ha, C. S., Shin M. H., \& Kim B. G. (2006). Analysis of ground reaction force set up to shooting position for improve performance archers. Korean Journal of Sports Science, 15(1), 817-828.

Hah C. K., \& Yi J. H. (2008). Evaluation on kinematic factors affecting scores of Olympic round game. during the follow through in archery. Korean Journal of Sport biomechanics. 18, 227-234.

Kim B. H., Song J. H., \& Kim K. J. (2008). Archery training guide for the disabled to improve performance. Korean Paralympic Committee.

Kim J. T., Lee S. J., \& Kim S. S (2014). Influence of rating of perceived exertion on kinematic characteristics in top class archery athletes. Journal of Coaching Development, 16(2), 99-106.

Kim J. H., \& Kim H. Y. (2005). Kinematic analysis on the release movement for expert archers. Korean Journal of Physical Education, 44(4), 415-424.

Kim J. H. (1996). The effect of the perception of rhythm of clicker sound on archer's records unpublished paper of masters degree. Korea National Sport University Graduate School.

Kim H. Y., \& Kim J. H. (2006). The consistency of an elite archer's shooting movement for improving his performance. Korean Journal of Physical Education, 45(5), 473-483.

Korean Paralympic Committee. (2015). 10 years of Korean Physical Education Association. Korean Paralympic Committee.

Lee J. H., Hah C. K., Ryu J. S., \& Kim K. C. (2007). Evaluation on motion features of the world's second archer during back-tension in archery. Korean Journal of Sport biomechanics, 17(3), 197-207.

Stuart J., \& Atha J. (1990). Postural consistency in skilled archers. Journal of Sports Sciences, 8, 223234.

World Archery (2020). Para Archery Classified Handbook, World Archery. 